\title{
Genomic Characterization of
} Multidrug-Resistant Salmonella Serovars Derby and Rissen From the Pig Value Chain in Vietnam

\begin{abstract}
Belén González-Santamarina ${ }^{1,2 *}$, Silvia García-Soto ${ }^{1}$, Sinh Dang-Xuan ${ }^{3,4}$, Mostafa Y. Abdel-Glil ${ }^{1}$, Diana Meemken ${ }^{5}$, Reinhard Fries ${ }^{5}$ and Herbert Tomaso ${ }^{1}$

${ }^{1}$ Institute of Bacterial Infections and Zoonoses, Friedrich-Loeffler-Institut, Jena, Germany, ${ }^{2}$ Institute of Institute of Molecular Pathogenesis, Friedrich-Loeffler-Institut, Jena, Germany, ${ }^{3}$ International Livestock Research Institute, Hanoi, Vietnam, ${ }^{4}$ Center for Public Health and Ecosystem Research, Hanoi University of Public Health, Hanoi, Vietnam, ${ }^{5}$ Institute of Food Safety and Food Hygiene, Section Meat Hygiene, Freie Universität Berlin, Berlin, Germany
\end{abstract}

Nontyphoidal Salmonella (NTS) is the most reported cause of bacterial foodborne zoonoses in Vietnam, and contaminated pork is one of the main sources of human infection. In recent years, the prevalence of NTS carrying multiple antimicrobial resistance genes (ARGs) have been increased. The genomic characterization along the pig value chain and the identification of ARGs and plasmids have the potential to improve food safety by understanding the dissemination of ARGs from the farm to the table. We report an analysis of 13 S. Derby and 10 S. Rissen isolates, collected in 2013 at different stages in Vietnamese slaughterhouses and markets. VITEK 2 Compact System was used to characterize the phenotypical antimicrobial resistance of the isolates. In addition, whole-genome sequencing (WGS) was used to detect ARGs and plasmids conferring multidrug resistance. Whole genome single nucleotide polymorphism typing was used to determine the genetic diversity of the strains and the spread of ARGs along the pig value chain. Altogether, $86.9 \%(20 / 23)$ of the samples were resistant to at least one antibiotic. Resistance to ampicillin was most frequently detected (73.9\%), followed by piperacillin and moxifloxacin (both 69.6\%). At least one ARG was found in all strains, and 69.6\% (16/23) were multidrug-resistant (MDR). The observed phenotype and genotype of antimicrobial resistance were not always concordant. Plasmid replicons were found in almost all strains [95.6\% (22/23)], and the phylogenetic analysis detected nine clusters (S. Derby, $n=5$; S. Rissen, $n=4$ ). ARGs and plasmid content were almost identical within clusters. We found six MDR IncHl1s with identical plasmid sequence type in strains of different genetic clusters at the slaughterhouse and the market. In conclusion, high rates of multidrug resistance were observed in Salmonella strains from Vietnam in 2013. Genomic analysis revealed many resistance genes and plasmids, which have the potential to spread along the pig value chain from the slaughterhouse to the market. This study pointed out that bioinformatics analyses of WGS data are essential to detect, trace back, and control the MDR strains along the pig value chain. Further studies are necessary to assess the more recent MDR Salmonella strains spreading in Vietnam. 


\section{INTRODUCTION}

Nontyphoidal Salmonella (NTS) are among the most important foodborne pathogens worldwide (1). NTS infections were reported as the major cause of diarrhea in Vietnamese children and severe invasive infections in adults (2). NTS can be host generalists, infecting a broad range of vertebrates, including pigs (3). Pork is the most frequently consumed meat in Vietnam, but pigs commonly harbor this pathogen without showing clinical signs (4). The overall prevalence of Salmonella in pigs in Vietnam was $69.7 \%$ (5), and it varies at the different steps of the pig value chain. The prevalence in pig pen floors is between $27.7 \%$ (6) and $36.1 \%$ (4), and in slaughterhouses, pig carcasses are frequently contaminated (38.9 to $95.7 \%)(4,7)$. Another relevant stage in the pig value chain are the markets. In Vietnam, fresh meat is usually bought on a traditional market, where it is displayed on tables or stands at ambient temperature (8). On pork markets, the prevalence of Salmonella in cut pork varied between 28.6 and $44.4 \%$ (4).

In Vietnam and in other Asian countries, Salmonella Rissen (S. Rissen) is the most prevalent serovar in pigs and in human patients with diarrhea (8). This serovar is also the most detected in pork, beef (5), and shrimp batches (2). Another important serovar is $S$. Derby, detected in pig lymph nodes with a prevalence of $50 \%$ (9). It was also detected in Vietnamese pig farms, pig carcasses in slaughterhouses, and pork in the market (4).

Antimicrobial resistance (AMR) transferred by bacteria is one of the greatest threats to both human and animal health (10). Humans can acquire bacterial infections encoding AMR genes (ARGs) through the consumption or handling of contaminated food (2). Multidrug-resistant bacterial isolates exhibit resistance to at least one agent in three or more antimicrobial families (11). In studies about the food distribution system in Vietnam, multidrug-resistant (MDR) Salmonella strains were widely disseminated in retail meat and seafood (13) \#185; (12) \#173; (5) \#174. In retail meat, 52 to $92.8 \%$ of the samples were resistant to at least one antibiotic, and between 36 and 64.3\% carried MDR Salmonella $(12,13)$. In seafood, 50 and $37.5 \%$ of fish and shrimps' samples were resistant, respectively (5).

Resistance against tetracycline, trimethoprimsulfamethoxazole, chloramphenicol, and ampicillin is the most commonly reported in Salmonella isolates collected from pork, other retail meat, and food products in Vietnam $(5,9,12)$. Furthermore, in Vietnam, Extended Spectrum Beta-Lactamase (ESBL)- and AmpC-producing Salmonella isolates have been detected in food (5) and mor-1 in poultry meat (14). This high MDR prevalence could be related to the use of large amounts of antimicrobials to treat infections, as well as to increase the productivity of animal farming (8). Horizontal gene transfer plays an important role in the spread of AMR in bacterial populations (15). The most common vehicles linked to the dissemination of ARGs are plasmids with a wide range of sizes $(15,16)$. In Salmonella, the most common conjugative plasmids are those that belong to incompatibility groups (Inc) IncI, IncFI, IncN, and IncH (16), which carry a great variety of ARGs (17).
During the last years, whole-genome sequencing (WGS) has been shown to be useful for genetic characterization of Salmonella isolates including serovar prediction (18). To our knowledge, WGS is not yet established in Vietnam for NTS analysis, and most of the studies still rely on conventional microbiological methods (19).

In this study, we used WGS and bioinformatics analysis to decipher the genetic traits (ARGs and plasmid replicons) of $S$. Derby and S. Rissen isolates collected in 2013 in Vietnam at different stages of the pig value chain (pig slaughterhouses and pork markets). We performed phenotypic characterization and AMR testing, as well as a phylogenetic analysis using a distance matrix based on single-nucleotide polymorphisms (SNPs). We also predicted AMR based on WGS data. Plasmids carrying ARGs were traced for potential dissemination through the pig value chain. The aim of this study was to show that WGS could potentially help to detect and to control the dissemination of ARGs from the farm to the table in Vietnam.

\section{MATERIALS AND METHODS}

\section{Bacterial Strains, Isolation, and Identification}

In this study, 23 Salmonella isolates (13 S. Derby and 10 S. Rissen) were analyzed. They were collected from diverse positions in pig slaughterhouses and pork markets in Hung Yen province in Vietnam in 2013 (Table 1). These strains were provided by Univ.-Prof. i. R. Dr. Reinhard Fries from the Institute of Food Safety and Food Hygiene Working Group Meat Hygiene of Freie Universität Berlin (FU). They were isolated and serotyped following the DIN EN ISO 6579-1:2017-07 in 2013 and stored on glycerol or cryotubes at $-20^{\circ} \mathrm{C}$. In July 2019 , these strains were transferred from the Institute of Food Safety and Food Hygiene, Working Group Meat Hygiene, FU, to the Institute of Bacterial Infections and Zoonoses (IBIZ, Jena) under appropriate shipping conditions.

Isolates were resuspended in $3 \mathrm{~mL}$ of brain heart infusion broth (Mast Diagnostica GmbH, Reinfeld, Germany) and incubated between 4 and $18 \mathrm{~h}$ at $37^{\circ} \mathrm{C}$. They were cultivated on RAMBACH ${ }^{\circledR}$ Agar (Merck KGaA, Darmstadt, Germany) for 24 $\pm 3 \mathrm{~h}$ at $37^{\circ} \mathrm{C}$. The cultures were not contaminated, and the colonies had a characteristic red-pink color with a bright edge.

\section{Antimicrobial Susceptibility Testing}

The isolates were recultivated on Columbia blood plates for $24 \mathrm{~h}$ at $37^{\circ} \mathrm{C}$. Antimicrobial susceptibility test (AST) of the strain was assessed by determining the minimum inhibitory concentration (MIC) using the VITEK 2 Compact System (bioMérieux, Marcy-l'Étoile, France). VITEK cards AST-N195 and AST-N248 were employed to determine MIC values $(\mathrm{mg} / \mathrm{L}$ ) according to the European Committee on Antimicrobial Susceptibility Testing (EUCAST) guidelines (20). Twenty-four different antibiotics were evaluated: ampicillin, amoxicillin-clavulanic acid, piperacillin, piperacillin-tazobactam, cefalexin, cefuroxime, cefuroxime-axetil, cefotaxime, ceftazidime, cefepime, aztreonam, ertapenem, imipenem, meropenem, amikacin, gentamicin, tobramycin, ciprofloxacin, tigecycline, fosfomycin, 
TABLE 1 | Bioinformatics results of the 23 isolates of Salmonella enterica subsp. enterica serovar Derby and Rissen.

\begin{tabular}{|c|c|c|c|c|c|c|c|}
\hline \multicolumn{4}{|l|}{ Metadata } & \multicolumn{2}{|r|}{ Antibiotic resistance genes } & \multicolumn{2}{|r|}{ Plasmid } \\
\hline Serovar & ST & ID strain & Sample & $\boldsymbol{n}$ & Gene names & $\boldsymbol{n}$ & Replicon name \\
\hline S. Derby & 40 & $19 \mathrm{CS} 0392$ & $\begin{array}{l}\text { Slaughterhouse worker } \\
\text { hands }\end{array}$ & 12 & $\begin{array}{l}\text { bla TEM.1, aadA1, aadA2, gnrS1, fosA7.3, dfrA12, sul2, sul3, } \\
\text { tetA, tetM, cmIA1, floR }\end{array}$ & 0 & 0 \\
\hline S. Derby & 40 & $19 \mathrm{CS} 0393$ & $\begin{array}{l}\text { Swab on pig carcass at } \\
\text { slaughterhouse }\end{array}$ & 12 & $\begin{array}{l}\text { bla } \text { TEM.1, }_{\text {ad }} \text { a1, aadA2, gnrS1, fosA7.3, dfrA12, sul2, sul3, } \\
\text { tetA, tetM, cmlA1, floR }\end{array}$ & 1 & Col440I_1 \\
\hline S. Derby & 40 & $19 \mathrm{CS} 0395$ & Pork at market & 12 & $\begin{array}{l}\text { bla }{ }_{T E M .1} \text {, aadA1, aadA2, gnrS1, fosA7.3, dfrA12, sul2, sul3, } \\
\text { tetA, tetM, cmIA1, floR, }\end{array}$ & 1 & Col440I_1 \\
\hline S. Derby & 40 & $19 \mathrm{CS} 0397$ & Skin on pig carcass & 13 & $\begin{array}{l}\text { bla TEM.1, bla LAP2, aac(3)-Ild, aadA1, aadA2, gnrS1, fosA7.3, } \\
\text { dfrA12, sul2, sul3, tetA, cmIA1, mefB }\end{array}$ & 2 & ColRNAl_1, IncFIB.K._1_Kpn3 \\
\hline S. Derby & 40 & $19 C S 0399$ & $\begin{array}{l}\text { Slaughterhouse worker } \\
\text { hands }\end{array}$ & 13 & $\begin{array}{l}\text { bla } \\
\text { TfEM.1, bla } \text { LAP2 }_{\text {LA }} \text { aac(3)-IId, aadA1, aadA2, sul3, tetA, cmIA1, mefB }\end{array}$ & 2 & Col440II_1, IncFIB.K._1_Kpn3 \\
\hline S. Derby & 40 & $19 \mathrm{CS} 0400$ & Pork at market & 7 & blateM.1, anrS1, fosA7.3, sul2, tetA, tetM, floR & 5 & $\begin{array}{l}\text { IncHI1A_1, IncHI1B.R27._1_R27IncFIA.HI1._1_HI1, } \\
\text { Col440I_1, ColRNAI_1 }\end{array}$ \\
\hline S. Derby & 40 & $19 \mathrm{CS} 0401$ & Pork at market & 7 & bla & 5 & $\begin{array}{l}\text { IncHl1A_1, IncHI1B.R27._1_R27IncFIA.HI1._1_HI1, } \\
\text { Col440I_1, ColRNAI_1 }\end{array}$ \\
\hline S. Derby & 40 & $19 \mathrm{CS} 0402$ & Pork at market & 11 & $\begin{array}{l}\text { bla }{ }_{T E M .1} \text {, aadA1, aadA2, gnrS1, fosA7.3, dfrA12, sul2, sul3, } \\
\text { tetA, tetM, cmIA1, floR }\end{array}$ & 5 & $\begin{array}{l}\text { IncHI1A_1, IncHI1B.R27._1_R27IncFIA.HI1._1_HI1, } \\
\text { Col440I_1, ColRNAI_1 }\end{array}$ \\
\hline S. Derby & 40 & $19 \mathrm{CS} 0403$ & Pork at market & 7 & blateM.1, fosA7.3, qnrS1, sul2, floR, tetA, tetM & 5 & $\begin{array}{l}\text { IncHl1A_1, IncHl1B.R27._1_R27IncFIA.HI1._1_HI1, } \\
\text { Col440I_1, ColRNAI_1 }\end{array}$ \\
\hline S. Derby & 40 & 19CS0404 & Pork at market & 8 & aadA1, aadA2, anrS1, fosA7.3, dfrA12, sul3, tetM, cmlA1 & 2 & IncHI1A_1, IncHI1B.R27._1_R27 \\
\hline S. Derby & 40 & $19 \mathrm{CS} 0418$ & $\begin{array}{l}\text { Cutting board at pork } \\
\text { shop }\end{array}$ & 13 & 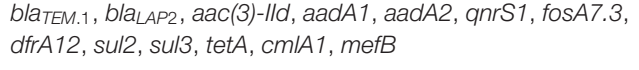 & 2 & IncFIB.K._1_Kpn3, Col440II_1 \\
\hline S. Derby & 40 & $19 \mathrm{CS} 0419$ & Pork at market & 12 & $\begin{array}{l}\text { bla TEM.1, aadA1, aadA2, gnrS1, fosA7.3, dfrA12, sul2, sul3, } \\
\text { tetA, tetM, cmIA1, floR }\end{array}$ & 1 & Col440I_1 \\
\hline S. Derby & 40 & $19 \mathrm{CS} 0424$ & $\begin{array}{l}\text { Slaughterhouse worker } \\
\text { hands }\end{array}$ & 12 & $\begin{array}{l}\text { bla }{ }_{T E M .1} \text {, aadA1, aadA2, fosA7.3, gnrS1, dfrA12, sul2, sul3, } \\
\text { tetA, tetM, cmIA1, floR }\end{array}$ & 1 & Col440I_1 \\
\hline S. Rissen & 469 & $19 \mathrm{CS} 0394$ & Pork at market & 1 & tetA & 2 & Col440II_1, ColRNAI_1 \\
\hline S. Rissen & 469 & $19 \mathrm{CS} 0396$ & $\begin{array}{l}\text { Swab on pig carcass at } \\
\text { slaughterhouse }\end{array}$ & 1 & tet $A$ & 2 & Col440II_1, ColRNAI_1 \\
\hline S. Rissen & 469 & $19 \mathrm{CS} 0398$ & $\begin{array}{l}\text { Splitting place at pig } \\
\text { slaughterhouse }\end{array}$ & 1 & tetA & 5 & Col440II_1, ColRNAI_1 \\
\hline S. Rissen & 469 & $19 \mathrm{CS} 0416$ & Skin in carcass & 8 & blateM.1, aac(3)-Ild, aadA2, mcr-1, tetA, tetM, floR, InuF & 7 & $\begin{array}{l}\text { IncFIB.AP001918._1, IncFIC.FIl._1, Incl2_1_Delta, } \\
\text { Col.BS512._1, Col156_1, Col440II_1, ColRNAI_1 }\end{array}$ \\
\hline S. Rissen & 469 & $19 \mathrm{CS} 0417$ & $\begin{array}{l}\text { Splitting place at pig } \\
\text { slaughterhouse }\end{array}$ & 10 & $\begin{array}{l}\text { bla }{ }_{T E M} \text {.1 , aadA1, aadA2, anrS1, dfrA12, sul2, sul3, tetM, } \\
\text { cmIA1, floR }\end{array}$ & 4 & $\begin{array}{l}\text { IncHI1A_1, IncHI1B.R27._1_R27, Col440II_1, } \\
\text { ColRNAI_1 }\end{array}$ \\
\hline S. Rissen & 469 & $19 \mathrm{CS} 0420$ & Pork at market & 1 & tetA & 2 & Col440II_1, ColRNAl_1 \\
\hline S. Rissen & 469 & $19 \mathrm{CS} 0421$ & Pork at market & 1 & tetA & 2 & Col440II_1, ColRNAI_1 \\
\hline S. Rissen & 469 & $19 \mathrm{CS} 0422$ & Pork at market & 8 & blateм.1, aadA1, aadA2, dfrA12, sul1, sul3, tetA, cmlA1 & 3 & IncY_1, Col440II_1, ColRNAI_1 \\
\hline S. Rissen & 69 & $19 \mathrm{CS} 0423$ & $\begin{array}{l}\text { Swab on pig carcass at } \\
\text { slaughterhouse }\end{array}$ & 1 & tet $A$ & 2 & Col440II_1, ColRNAI_1 \\
\hline S. Rissen & 469 & $19 \mathrm{CS} 0425$ & $\begin{array}{l}\text { Slaughterhouse worker } \\
\text { hands }\end{array}$ & 1 & tet $A$ & 2 & Col440II_1, ColRNAI_1 \\
\hline
\end{tabular}


colistin, trimethoprim, and trimethoprim-sulfamethoxazole. VITEK 2 Compact System (bioMérieux, Marcy-l'Étoile, France) also detected the EUCAST epidemiological cutoff values (ECOFFs). Here the 24 antibiotics are enclosed in seven antimicrobial families: $\beta$-lactam antibiotics, aminoglycosides, quinolone, fosfomycin, trimethoprim/sulfonamide, polypeptide, and tetracycline. MIC values $(\mathrm{mg} / \mathrm{L})$ of fosfomycin in $S$. Derby isolates were also tested with Micronaut AST-system plate M/E1055-040 (MERLIN Diagnostika, Bornheim-Hersel, Germany) following the manufacturer's instructions and according to EUCAST guidelines. Turbidity reading and interpretation were done manually.

\section{Whole-Genome Sequencing}

For sequencing, the 23 Salmonella isolates were grown overnight at $37^{\circ} \mathrm{C}$ in $3 \mathrm{~mL}$ of Luria-Bertani broth (Mast Diagnostica $\mathrm{GmbH}$, Reinfeld, Germany). DNA extraction was performed using the DNeasy blood and tissue kit (QIAGEN GmbH, Hilden, Germany) following the manufacturer's instructions for Gramnegative bacteria. DNA sequencing libraries were constructed using the Nextera XT Preparation Kit (Illumina Inc., San Diego, CA) following the manufacturer's instructions. Pairedend sequencing was performed on an Illumina MiSeq platform (Illumina Inc.) using a 300-cycle MiSeq reagent kit.

One strain (19CS0402) was additionally sequenced using the MinION platform to analyze the complete genome sequence and the plasmid structure. High-molecular-weight DNA was extracted using Genomic-tip 100/G and genomic DNA buffer kit (QIAGEN GmbH). The sequencing library was prepared using the Oxford Nanopore Technologies 1D Ligation Sequencing Kit (SQK-LSK109) with the Native Barcoding Expansion Kit (EXPNBD104) as recommended by the manufacturer.

\section{Bioinformatics Analysis}

We performed bioinformatics analysis of the strains using an in-house Linux-based bioinformatics pipeline called WGSBAC v.2.0 (available in its last version https://gitlab.com/FLI_Bioinfo/ WGSBAC/). WGSBAC takes as input Illumina raw pairedend reads, and the quality of the sequences is checked using FastQC v0.11.7 (http://www.bioinformatics.babraham.ac. $\mathrm{uk} /$ projects/fastqc/). The coverage of the raw reads is estimated theoretically as the total number of sequenced bases/reference genome size using an adapted script (https:/github.com/ raymondkiu/fastq-info/blob/master/fastq_info_3.sh). Reads are de novo assembled using Shovill v.1.0.4 (21) and evaluated by QUAST v.5.0.2 (22) in standard settings. Annotation is performed with Prokka v.1.14.5 (23), and to identify contamination, the pipeline uses Kraken 2 v.1.1 (24) and Kraken2DB to classify both reads and contigs. Acquired ARGs are detected using the software AMRFinderPlus v.3.6.10 (25). Additionally, ABRicate v.0.8.10 (available at https://github.com/ tseemann/abricate) with the databases CARD v.3.0.8 (26) and ResFinder v.3.2 (27) is used for the detection of ARGs. For the identification of plasmid replicon, ABRicate uses PlasmidFinder v.2.0.1 (28). For in silico serotyping, the WGSBAC pipeline relies on SISTR v.1.0.2 (29). For genotyping, WGSBAC uses classic multilocus sequence typing (MLST) using the software mlst v.2.16.1 on assembled genomes. For plasmid typing, we used the plasmid MLST (pMLST) 2.0 external server v.1.3 with the plasmid PubMLST database (https://pubmlst.org/plasmid/).

Furthermore, WGSBAC uses Snippy v.4.3.6 for core-genome SNP (cgSNP) detection. FastTree v.2.1.10 (30) uses the SNP distance matrix obtained by Snippy v.2.1.10 (30) to build a cgSNP-based phylogenetic tree. For visualization of the phylogenetic trees, we employed the online tool iTOL v.5.1.0 (31).

The IncHI1 plasmid-positive strain 19CS0402 (p19CS0402IncHI1) was sequenced using an Illumina MiSeq platform (Illumina Inc.), as well as with a MinION sequencer (Oxford Nanopore Technologies, Oxford, United Kingdom) to close sequences of the chromosome and the plasmid. The raw FAST5 files from the MinION were processed using the Guppy toolkit v.3.4.1 (Oxford Nanopore Technologies). The Guppy command guppy_basecaller was used for base-calling, and guppy_barcoder was used for demultiplexing. De novo assembly for long sequencing reads was performed using Flye v.2.6 (32). Assembly polishing was performed first using the long reads in four rounds by Racon v.1.4.3 (33) and one final round with Medaka v.0.10.0. Next, Illumina reads were trimmed using Trimmomatic v.0.39, and Pilon v.1.23 (34) was used to correct the assembled data obtained with the MinION with the trimmed Illumina reads using standard settings.

To compare the IncHI1 plasmids of the same plasmid ST replicon, the whole p19CS0402-IncHI1 (Figure 1) sequence was mapped against the Illumina draft sequences carrying the same replicon. The multiple alignment was performed by the algorithm Mauve (35) within the external software Geneious Prime v.11.1.5 (Biomatters, Ltd., Auckland, New Zealand). Annotation was performed with Prokka v.1.14.5 (23) (Supplementary Table 1).

\section{RESULTS}

\section{Serovar Prediction and Genotyping}

The in silico serotyping tool SISTR (v1. 0.2) confirmed all serotyped isolates as $S$. Derby $(n=13)$ with antigen formula 1,4,5,[12]:f,g:-, according to the White-Kauffmann-Le Minor scheme (36). In addition, all the isolates serotyped as $S$. Rissen $(n=10)$ were confirmed as serovar Rissen with the antigenic formula 6,7,14:f,g:-. Classic MLST revealed sequence type (ST) 40 [aroC (19), dnaN (20), hemD (3), hisD (20), purE(5), sucA (23), and thrA (23)] for all S. Derby strains and ST469 for all $S$. Rissen isolates [aroC (92), dnaN (107), hemD (79), hisD (156), purE (64), sucA (151), and thrA (87)] (Table 1).

\section{Antimicrobial Susceptibility Testing}

The 23 isolates were successfully processed with the VITEK 2 Compact System (bioMérieux, Marcy-l'Étoile, France) to determine the MIC $(\mathrm{mg} / \mathrm{L})$ values of 24 different antibiotics. Eighty-seven percent $(20 / 23)$ of the samples were resistant to at least one antibiotic (Table 2). The most frequently detected resistance was against ampicillin (73.9\%) and piperacillin and moxifloxacin (both 69.6\%), followed by trimethoprim and trimethoprim with sulfamethoxazole (both 56.5\%, Table 2). Resistance to cefuroxime-acetyl, gentamicin, tobramycin, and 


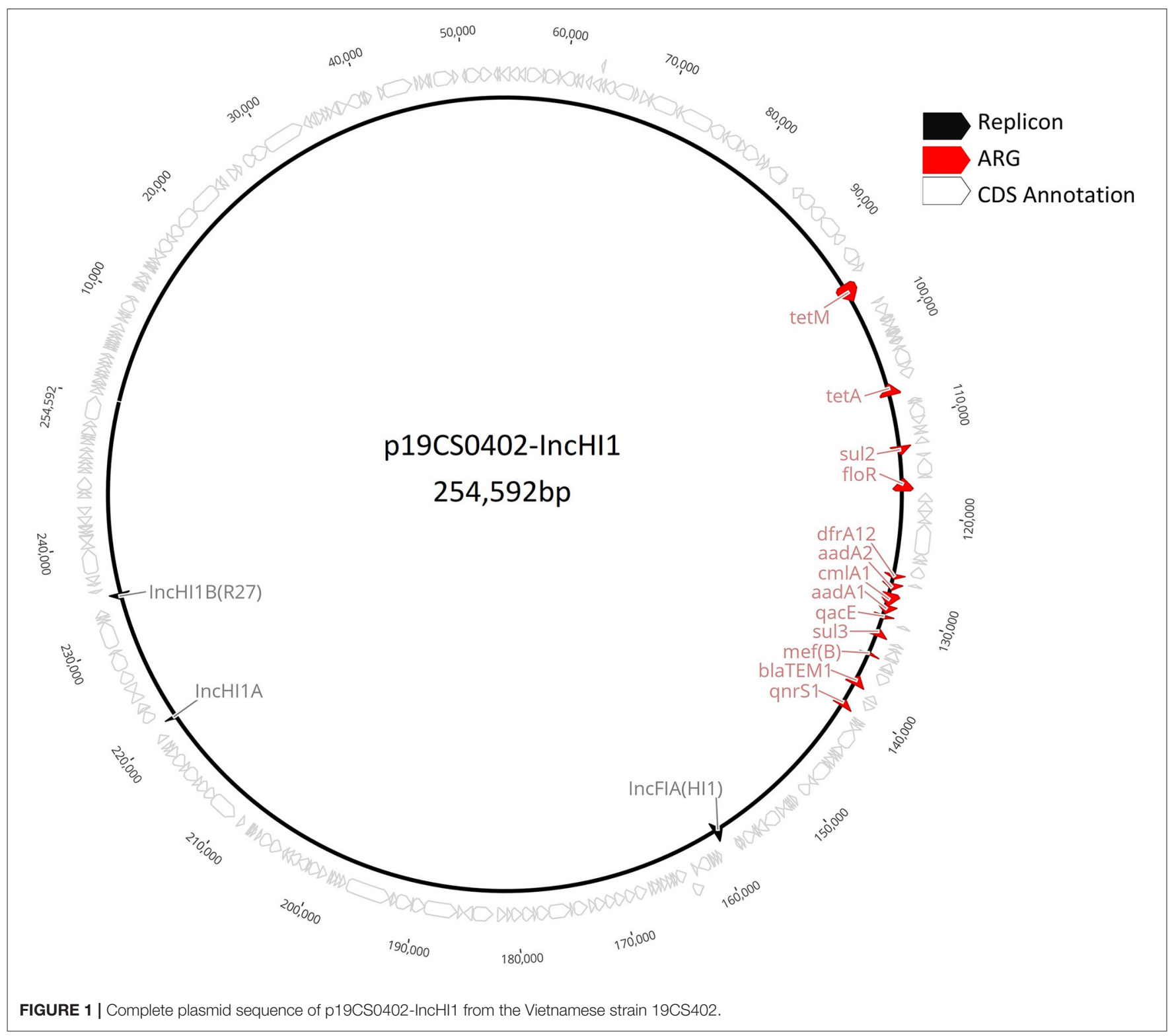

tigecycline was found in $17.4 \%$ isolates, followed by ciprofloxacin (13\%) and colistin (4.3\%, Table 2). The antibiotics categorized as "susceptible, increased exposure" (new intermediate nomenclature by EUCAST) (37) were amoxicillin-clavulanic acid $(65.2 \%)$, tigecycline $(21.7 \%)$, and piperacillin-tazobactam (4.3\%). All other tested antibiotics were classified as susceptible (standard dosing regimen) (Table 2; Supplementary Table 2).

\section{ARG Detection}

ARGs were found in all isolates (Table 1). They belonged to 11 antibiotics classes (Table 3): tetracycline (100\%; tet A and/or tetM), $\beta$-lactam antibiotics $\left(65.2 \% ; b l a_{T E M .1}\right.$ and/or $\left.b l a_{L A P}\right)$, chloramphenicol (69.6\%; cmlA1 and/or floR), sulfonamide (65.2\%; sul1, sul2, and/or sul3), quinolone (60.9\%; qnrS1), aminoglycoside (56.5\%; aadA1, aadA2, and/or aac(3)-IId), fosfomycin (56.5\%; fosA7.3), trimethoprim (52.5\%; dfrA12) macrolide $[13 \% ; m e f(B)]$, polypeptide $(4.3 \%, m c r-1)$, and lincosamide $(4.3 \%$; $\ln u F)$ (Table 3). All $S$. Derby isolates carried ARGs to at least six different antibiotics classes ( $\beta$-lactam antibiotics, quinolone, fosfomycin, trimethoprim-sulfonamide, tetracycline, and chloramphenicol). However, the only ARG present in all S. Rissen was against tetracyclines (Table 1).

\section{Comparison of Phenotypic and Genotypic Antimicrobial Profiles}

The correlation between the phenotypic resistance and the ARGs was compared. Discrepant results between the detected phenotype and the genotype were found in 20 isolates. The most discordant results were found in aminoglycosides, tetracycline, and fosfomycin (Table 4). In the case of aminoglycosides, 19 strains were detected as wild type, but nine of them carried two 
TABLE 2 | AST results of the 23 Salmonella isolates.

\begin{tabular}{|c|c|c|c|c|c|c|c|}
\hline Antibiotic class & Antibiotic & \multicolumn{2}{|c|}{ Resistant } & \multicolumn{2}{|c|}{ Susceptible, increased exposure (I) } & \multicolumn{2}{|c|}{ Susceptible } \\
\hline & AMC & - & - & 15 & $65.2 \%$ & 8 & $34.8 \%$ \\
\hline & PIP & 16 & $69.6 \%$ & - & - & 7 & $30.4 \%$ \\
\hline & PIT & - & - & 1 & $4.3 \%$ & 22 & $95.7 \%$ \\
\hline & CURA & 4 & $17.4 \%$ & - & - & 19 & $82.6 \%$ \\
\hline & CTA & - & - & - & - & 23 & $100 \%$ \\
\hline & $\mathrm{CTZ}$ & - & - & - & - & 23 & $100 \%$ \\
\hline & CEP & - & - & - & - & 23 & $100 \%$ \\
\hline & AZT & - & - & - & - & 23 & $100 \%$ \\
\hline & GEN & 4 & $17.4 \%$ & - & - & 19 & $82.6 \%$ \\
\hline & TOB & 4 & $17.4 \%$ & - & - & 19 & $82.6 \%$ \\
\hline \multirow[t]{2}{*}{ Quinolones } & $\mathrm{CIP}$ & 3 & $13.0 \%$ & - & - & 20 & $87.0 \%$ \\
\hline & MOX & 16 & $69.6 \%$ & - & - & 9 & $39.1 \%$ \\
\hline Fosfomycin & FOS & - & - & - & - & 23 & $100 \%$ \\
\hline \multirow[t]{2}{*}{ Trimethoprim/sulfamethoxazole } & TRI & 13 & $56.5 \%$ & - & - & 10 & $43.5 \%$ \\
\hline & $\mathrm{T} / \mathrm{S}$ & 13 & $56.5 \%$ & - & - & 10 & $43.5 \%$ \\
\hline Polymyxins & COL & 1 & $4.3 \%$ & - & - & 22 & $95.7 \%$ \\
\hline Tetracyclines & TIG & 4 & $17.4 \%$ & 5 & $21.7 \%$ & 14 & $60.9 \%$ \\
\hline
\end{tabular}

AMP, ampicillin; AMC, amoxicillin/clavulanic acid; PIP, piperacillin; PIT, piperacillin-tazobactam; CLE, cefalexin; CUR, cefuroxime; CURA, cefuroxime axetil; CTA, cefotaxime; CTZ, ceftazidime; CEP, cefepime; AZT, aztreonam; ERT, ertapenem; IMI, imipenem; MER, meropenem; AMI, amikacin; GEN, gentamicin; TOB, tobramycin; CIP, ciprofloxacin; MOX, moxifloxacin; TRI, trimethoprim; TRS, trimethoprim-sulfamethoxazole; TIG, tigecycline; FOS, fosfomycin; COL, colistin.

TABLE 3 | Resistance genes of the 23 isolates of Salmonella enterica subsp. enterica serovar Derby and Rissen.

\begin{tabular}{|c|c|c|c|}
\hline Resistance antibiotic families & Total \% & Genes & $\%$ \\
\hline \multirow[t]{2}{*}{ Tetracycline } & 100 & tet $A$ & 91.3 \\
\hline & & tetM & 52.2 \\
\hline \multirow[t]{2}{*}{$\beta$-Lactams } & 65.2 & bla TEM.1 & 65.2 \\
\hline & & bla $L A P$ & 13 \\
\hline \multirow[t]{2}{*}{ Chloramphenicol } & 69.6 & $\mathrm{~cm} / \mathrm{A} 1$ & 52.2 \\
\hline & & $f l o R$ & 47.8 \\
\hline \multirow[t]{3}{*}{ Sulfonamide } & 65.2 & sul1 & 4.3 \\
\hline & & sul2 & 56.5 \\
\hline & & sul3 & 52.2 \\
\hline Quinolone & 60.9 & qnrS1 & 60.9 \\
\hline \multirow[t]{3}{*}{ Aminoglycoside } & 56.2 & $\operatorname{aad} A 1$ & 52.2 \\
\hline & & aadA2 & 56.5 \\
\hline & & aac(3)-IId & 17.4 \\
\hline Fosfomycin & 56.5 & fosA7.3 & 56.5 \\
\hline Trimethoprim & 52.2 & dfrA12 & 52.2 \\
\hline Macrolide & 13 & $\operatorname{mef}(B)$ & 13 \\
\hline Polypeptide & 4.3 & $m c r-1$ & 4.3 \\
\hline Lincosamide & 4.3 & InuF & 4.3 \\
\hline
\end{tabular}

or three ARGs against aminoglycosides (Table 4). In addition, all the isolates had at least one ARG to tetracycline; nevertheless, 14 strains identified as wild type carried one or two genes against this antibiotic. Besides, all strains were identified as fosfomycin wild type and susceptible in the VITEK 2 Compact System (Table 4) and Micronaut AST-system, respectively (Supplementary Table 2). However, all the $S$. Derby strains carried fosA7.3 gene. S. Derby strains 19CS0419 and 19CS0424 (Table 4) carried different ARGs, but they were identified as wild type. In contrast, four S. Rissen isolates (19CS0394, 19CS0396, 19CS0398, and 19CS0425; Table 4) were classified as non-sensitive to $\beta$-lactam antibiotics, trimethoprimsulfonamide and quinolones, but no resistance genes were detected.

\section{Phylogenetic Analysis}

The phylogenetic distance among $S$. Derby strains was on average 89 SNPs (0-207 SNPs; Supplementary Table 3). They were grouped in six different clusters (Figure 2). Three clusters carried more than one strain (highlighted in different colors in Figure 2). Strains within the same cluster had a distance between up to six SNPs (Supplementary Table 3). Additionally, two of 
TABLE 4 | Comparison of antibiotic resistance phenotype and genotype of the 15 Salmonella Derby samples.

\begin{tabular}{|c|c|c|c|c|c|c|c|c|c|c|c|c|c|c|c|c|}
\hline \multicolumn{3}{|l|}{ Metadata } & \multicolumn{2}{|c|}{$\beta$-Lactam antibiotics } & \multicolumn{2}{|r|}{ Aminoglycoside } & \multicolumn{2}{|c|}{ Quinolone } & \multicolumn{2}{|c|}{ Fosfomycin } & \multicolumn{2}{|c|}{ Trimethoprim/sulfonamide } & \multicolumn{2}{|c|}{ Polypeptide } & \multicolumn{2}{|c|}{ Tetracycline } \\
\hline Serotype & ID strain & Sample & $\mathbf{P}$ & $\mathbf{G}$ & $\mathbf{P}$ & $\mathbf{G}$ & $\mathbf{P}$ & G & $\mathbf{P}$ & G & $\mathbf{P}$ & $\mathbf{G}$ & $\mathbf{P}$ & $\mathbf{G}$ & $\mathbf{P}$ & $\mathbf{G}$ \\
\hline S. Derby & 19CS0392 & $\begin{array}{l}\text { Slaughterhouse } \\
\text { worker hands }\end{array}$ & AP & bla TEM.1 & W & aadA1, aadA2 & PR & qnrS1 & W & fosA7.3 & $\mathrm{R}$ & sul2, sul3, dfrA12 & W & - & W & tetA, tetM \\
\hline S. Derby & $19 \mathrm{CS} 0393$ & $\begin{array}{l}\text { Swab on pig } \\
\text { carcass at } \\
\text { slaughterhouse }\end{array}$ & AP & bla TEM.1 & W & aadA1, aadA2 & $\mathrm{PR}$ & qnrS1 & W & fosA7.3 & $\mathrm{R}$ & sul2, sul3, dfrA12 & W & - & W & tetA, tetM \\
\hline S. Derby & 19CS0395 & Pork at market & AP & blateM.1 & W & aadA1, aadA2 & PR & qnrS1 & W & fosA7.3 & $\mathrm{R}$ & sul2, sul3, dfrA12 & W & - & W & tetA, tetM \\
\hline S. Derby & $19 \mathrm{CS} 0397$ & $\begin{array}{l}\text { Skin on pig } \\
\text { carcass }\end{array}$ & AP & blateM.1, bla & $\mathrm{R}$ & $\operatorname{aad} A 1, \operatorname{aad} A 2, \operatorname{aac}(3)-I I d$ & $\mathrm{R}$ & qnrS1 & W & fosA7.3 & $\mathrm{R}$ & sul2, sul3, dfrA12 & W & - & $\mathrm{R}$ & tetA \\
\hline S. Derby & 19CS0399 & $\begin{array}{l}\text { Slaughterhouse } \\
\text { worker hands }\end{array}$ & AP & bla TEM.1, bla & $\mathrm{R}$ & $\operatorname{aadA1}, \operatorname{aad} A 2$, , $\operatorname{aac}(3)-1 / d$ & $\mathrm{R}$ & qnrS1 & W & fosA7.3 & $\mathrm{R}$ & sul2, sul3, dfrA12 & W & - & $\mathrm{R}$ & tet $A$ \\
\hline S. Derby & $19 \mathrm{CS} 0400$ & Pork at market & AP & bla & W & - & $\mathrm{PR}$ & qnrS1 & W & fosA7.3 & W & sul2 & W & - & W & tetA, tetM \\
\hline S. Derby & $19 \mathrm{CS} 0401$ & Pork at market & AP & bla TEM.1 & W & - & PR & qnrS1 & W & fosA7.3 & W & sul2 & W & - & W & tetA, tetM \\
\hline S. Derby & 19CS0402 & Pork at market & AP & bla & W & aadA1, aadA2 & PR & qnrS1 & W & fosA7.3 & $\mathrm{R}$ & sul2, sul3, dfrA12 & W & - & W & tetA, tetM \\
\hline S. Derby & $19 \mathrm{CS} 0403$ & Pork at market & AP & blateM.1 & W & - & PR & qnrS1 & W & fosA7.3 & W & sul2 & W & - & W & tetA, tetM \\
\hline S. Derby & 19CS0404 & Pork at market & AP & - & W & aadA1, aadA2 & $\mathrm{R}$ & qnrS1 & W & fosA7.3 & $\mathrm{R}$ & sul3, dfrA12 & W & - & $\mathrm{R}$ & tetM \\
\hline S. Derby & $19 \mathrm{CS} 0418$ & $\begin{array}{l}\text { Cutting board at } \\
\text { pork shop }\end{array}$ & W & blatEM.1, bla & W & aadA1, aadA2, , aac(3)-IId, & W & qnrS1 & W & fosA7.3 & W & sul2, sul3, dfra12 & W & - & W & tetA \\
\hline S. Derby & $19 \mathrm{CS} 0419$ & Pork at market & W & blateM.1 & W & $\operatorname{aad} A 1$, aadA2 & W & qnrS1 & W & fosA7.3 & W & sul2, sul3, dfrA12 & W & - & W & tetA, tetM \\
\hline S. Derby & $19 \mathrm{CS} 0424$ & $\begin{array}{l}\text { Slaughterhouse } \\
\text { worker hands }\end{array}$ & W & bla TEM.1 & W & aadA1, aadA2 & W & qnrS1 & W & fosA7.3 & W & sul2, sul3, dfrA12 & W & - & $\mathrm{R}$ & tetA, tetM \\
\hline S. Rissen & 19CS0394 & Pork at market & AP & - & W & - & $\mathrm{PR}$ & - & W & - & $\mathrm{R}$ & - & W & - & W & tet $A$ \\
\hline S. Rissen & $19 \mathrm{CS} 0396$ & $\begin{array}{l}\text { Swab on pig } \\
\text { carcass at } \\
\text { slaughterhouse }\end{array}$ & AP & - & W & - & PR & - & W & - & $\mathrm{R}$ & - & W & - & W & tetA \\
\hline S. Rissen & $19 \mathrm{CS} 0398$ & $\begin{array}{l}\text { Splitting place at } \\
\text { pig } \\
\text { slaughterhouse }\end{array}$ & AP & - & $\mathrm{R}$ & - & $\mathrm{R}$ & - & W & - & $\mathrm{R}$ & - & W & - & $\mathrm{R}$ & tetA \\
\hline S. Rissen & $19 \mathrm{CS} 0416$ & Skin in carcass & AP & bla & $\mathrm{R}$ & $\operatorname{aad} A 2,, \operatorname{aac}(3)-\| l d$ & W & - & W & - & W & - & $\mathrm{R}$ & $m c r-1.1$ & $\mathrm{R}$ & tetA, tetM \\
\hline S. Rissen & $19 \mathrm{CS} 0417$ & $\begin{array}{l}\text { Splitting place at } \\
\text { pig } \\
\text { slaughterhouse }\end{array}$ & AP & bla TEM.1 & W & aadA1, aadA2 & PR & qnrS1 & W & - & $\mathrm{R}$ & sul2, sul3, dfrA12 & W & - & W & tetM \\
\hline S. Rissen & $19 \mathrm{CS} 0420$ & Pork at market & W & - & W & - & W & - & W & - & W & - & W & - & $\mathrm{R}$ & tetA \\
\hline S. Rissen & $19 \mathrm{CS} 0421$ & Pork at market & W & - & W & - & W & - & W & - & W & - & W & - & W & tetA \\
\hline S. Rissen & $19 \mathrm{CS} 0422$ & Pork at market & AP & blateM.1 & W & aadA1, aadA2 & W & - & W & - & $\mathrm{R}$ & sul1, sul3, dfrA12 & W & - & $\mathrm{R}$ & tet $A$ \\
\hline S. Rissen & $19 \mathrm{CS} 0423$ & $\begin{array}{l}\text { Swab on pig } \\
\text { carcass at } \\
\text { slaughterhouse }\end{array}$ & W & - & W & - & W & - & W & - & W & - & W & - & $\mathrm{R}$ & tet $A$ \\
\hline S. Rissen & $19 \mathrm{CS} 0425$ & $\begin{array}{l}\text { Slaughterhouse } \\
\text { worker hands }\end{array}$ & AP & - & W & - & PR & - & W & - & $\mathrm{R}$ & - & W & - & W & tet $A$ \\
\hline
\end{tabular}

P, phenotype determinate by VITEK Compact 2; G, genotype determinate by ResFinder; AD, acquired penicillinase; W, wild type; R, resistance; PR, partial resistance; I, intermediate. 


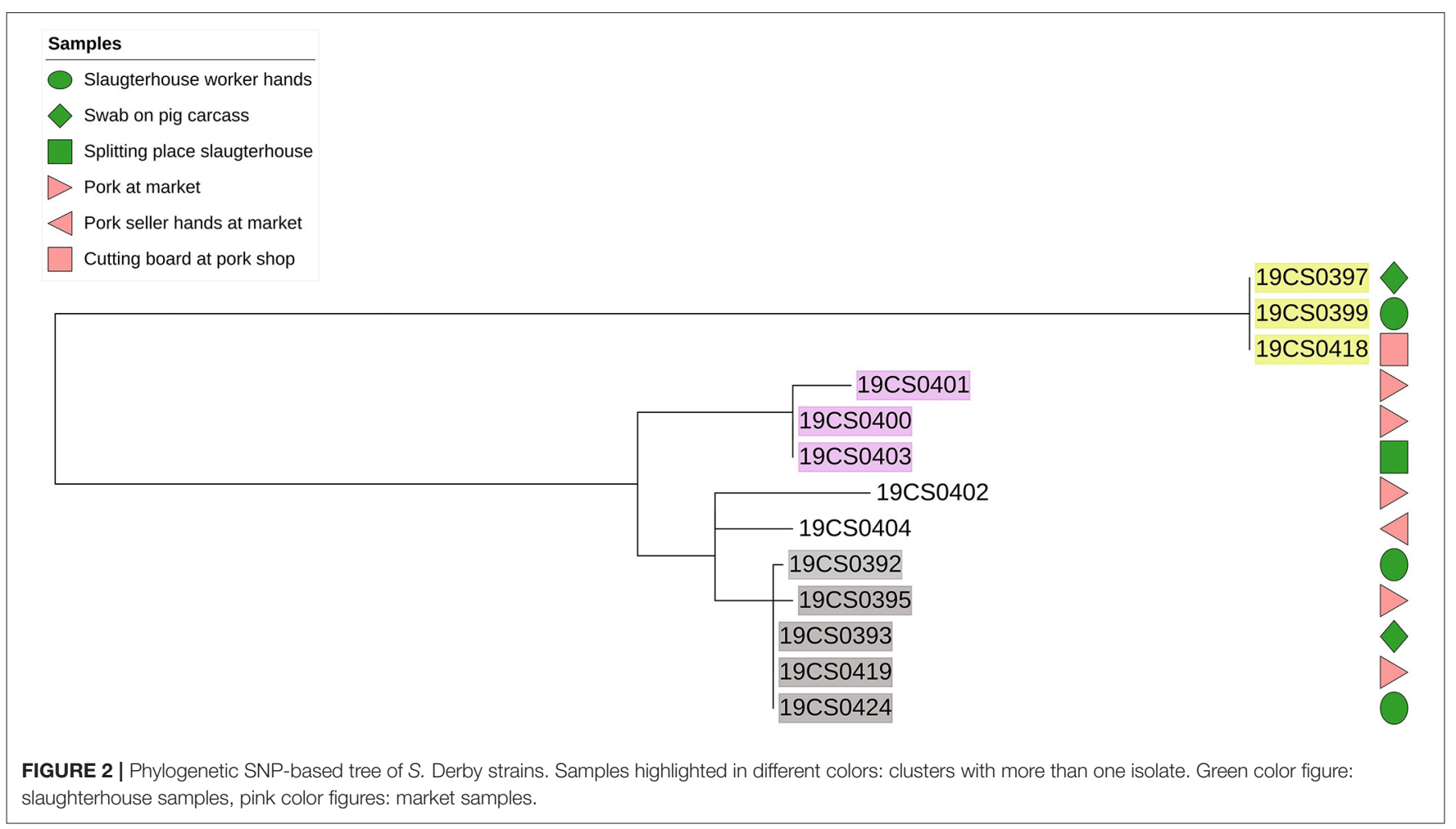

\section{Samples}

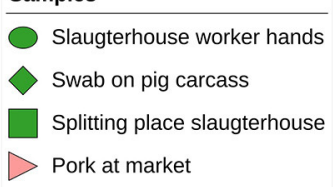

Pork at market

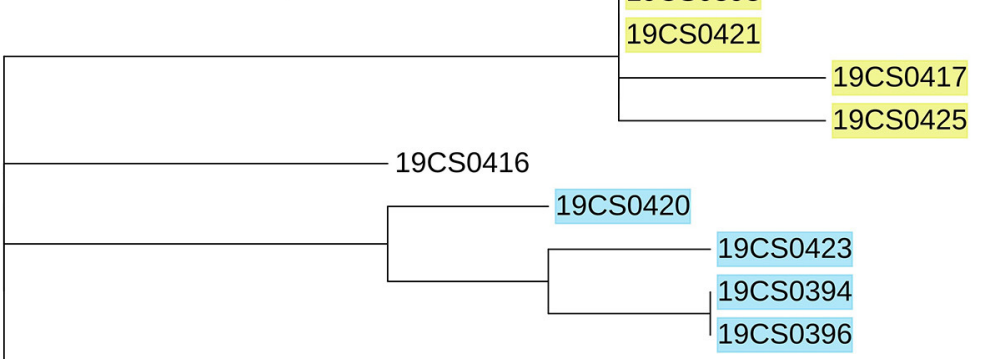

FIGURE 3 | Phylogenetic SNP-based tree of S. Rissen strains. Samples highlighted in different colors: clusters with more than one isolate. Green color figures: slaughterhouse samples, red color figures: market samples.

these clusters (yellow and gray highlight, Figure 2) contained strains taken in the slaughterhouses and markets.

The average of phylogenetic distance in $S$. Rissen strains was 32 SNPs (0-64 SNPs; Supplementary Table 3). They were grouped into four different clusters. Two of them contained strains taken in the slaughterhouse and the market (yellow and blue highlight, Figure 3). The distance among the $S$. Rissen strain clusters was up to six SNPs (Supplementary Table 3).

\section{Plasmid Replicon Identification}

The $95.6 \%(22 / 23)$ of the strains carried at least one plasmid replicon (Table $\mathbf{1}$ ). The most frequently detected replicons belong to the Col-plasmids (Col440II_1, Col440I_1, ColRNAI_1, Col.BS512._1 and Col156_1). They were detected in 91.3\% $(21 / 23)$ of the samples. Moreover, incompatibility group (Inc) replicons IncFI (IncFIA, IncFIB, and IncFIC) were found in $34.7 \%(8 / 23)$ of the isolates and IncHI1 [IncHI1A and 


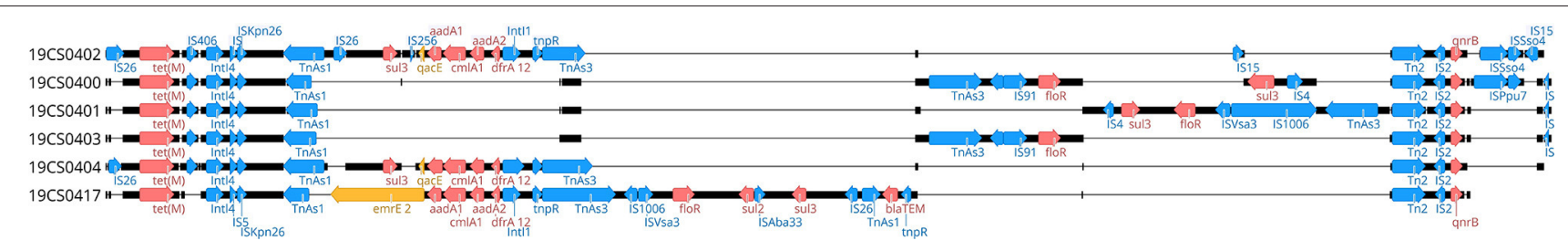

FIGURE 4 | Plasmids IncHI alignment of region, where ARGs are located. Blue annotation: mobile genetic elements [e.g., transposons (Tn) and insertion sequences (IS)]. Red annotations: resistance genes. Yellow annotations: efflux pumps or antiseptic resistance genes.

TABLE 5 | Isolates organized in clusters with information about the collection place, resistance genes, and plasmid replicons.

\begin{tabular}{|c|c|c|c|c|c|c|c|c|}
\hline Serovar & Cluster & \multicolumn{3}{|c|}{ Slaughterhouse } & \multicolumn{2}{|c|}{ Market } & \multicolumn{2}{|c|}{ WGS results } \\
\hline \multirow[t]{2}{*}{ Derby } & 1 & & $\begin{array}{l}19 \mathrm{CS} 0392^{*} \\
19 \mathrm{CS} 0424\end{array}$ & $19 \mathrm{CS} 0393$ & $\begin{array}{l}19 \mathrm{CS} 0395 \\
19 \mathrm{CS} 0419\end{array}$ & & $\begin{array}{l}\text { blaTEM.1, aadA1, aadA2, anrS1, } \\
\text { fosA7.3, dfrA12, sul2, sul3, tetA, } \\
\text { tetM, cmIA1, floR }\end{array}$ & */Col440I_1 \\
\hline & 3 & & & & $19 \mathrm{CSO} 0402$ & & $\begin{array}{l}\text { blaTEM.1, aadA1, aadA2, anrs1, } \\
\text { fosA7.3, dfrA12, sul2, sul3, tetA, } \\
\text { tetM, cmlA1, floR }\end{array}$ & $\begin{array}{l}\text { IncHI1A_1, } \\
\text { IncHI1B.R27._1_R27, } \\
\text { IncFIA.HI1._1_HI1, ,Col440I_1, } \\
\text { ColRNAI_1 }\end{array}$ \\
\hline \multirow[t]{4}{*}{ Rissen } & 1 & $19 \mathrm{CS} 0417^{*}$ & 19CSO425 & & $\begin{array}{l}19 C S 0421 \\
19 C S 0398\end{array}$ & & $\begin{array}{l}\text { blaTEM.1, aadA1, aadA2, gnrS1, } \\
\text { dfrA12, sul2, sul3, tetM, cmlA1, } \\
\text { floR*tetA }\end{array}$ & $\begin{array}{l}\text { IncHI1A, IncHI1B, Col440II_1, } \\
\text { ColRNAI_1 */Col440II_1, } \\
\text { ColRNAI_1 }\end{array}$ \\
\hline & 2 & & & $19 \mathrm{CS} 0416$ & & & $\begin{array}{l}\text { blaTEM.1, aac(3)-Ild, aadA2, } \\
\text { mcr-1, tetA, tetM, floR, InuF }\end{array}$ & $\begin{array}{l}\text { IncFIB.AP001918._1, } \\
\text { IncFIC.FII._1, Incl2_1_Delta, } \\
\text { Col.BS512._1, Col156_1, } \\
\text { Col440II_1, ColRNAl_1 }\end{array}$ \\
\hline & 3 & & & & $19 \mathrm{CS} 0420$ & & tetA & Col440II_1, ColRNAI_1 \\
\hline & 4 & & & $\begin{array}{l}19 \mathrm{CS} 0396 \\
19 \mathrm{CS} 0423\end{array}$ & $19 \mathrm{CS} 0394$ & & tetA & Col440II_1, ColRNAI_1 \\
\hline
\end{tabular}

In gray are the isolates carrying the identical IncHI.

*/solate belonging to a cluster, but it carries different resistance genes and/or plasmid replicons.

IncHI1B(R27)] in 26.1\% (6/23). In addition, IncI and IncY were detected once in single isolate each (Table 1).

pMLST analysis revealed six IncHI1 plasmid replicons with the identical (so far unknown) plasmid ST, which was closest to ST 16. The plasmid p19CS0402-IncHI1 carried also a IncFIA(HI1) replicon (Figure 1). The alignment of the six plasmids showed between 54.03 and $92.5 \%$ identity (Supplementary Table 4). The replicon IncFIA(HI1) was also detected in isolates 19CS0400, 19CS0401, and 19CS0403. Within the plasmids, differences in ARGs surrounded mobile genetic elements (MGEs) [insertion sites (IS) and transposons (Tn)] were found in a region of 81,503 bp (Figure 4). These plasmids carried between three and nine ARGs, and all sequences that contained tetM and qnrS1 were surrounded by similar MGEs (Figure 4). Between these two genes, other ARGs were located near MGEs. The isolate 19CS402 carried sul2, sul3, aad1, cmlA1, and aad2 (Figure 4). The isolate 19CS0417 contained additionally floR, bla $a_{\text {TEM }}$, and $e m r E$, which is a multidrug resistance antibiotic efflux pump (Figure 4). Moreover, 19CS402 and 19CS404 carried the qacE gene, which confers resistance to antiseptics. 


\section{Genetic Clusters and Their Occurrence in the Pig Value Chain}

SNP-based phylogeny revealed 10 clusters (Table 5). Five of them carried more than one isolate (three $S$. Derby and two $S$. Rissen). They were collected in the pig slaughterhouse (splitting place, worker's hand, and/or swab on pig carcass) and market (pork at market and/or cutting board) (Table 5). Almost all isolates of the same cluster carried the same ARGs and plasmid replicons. The only exceptions were 19CS392 (S. Derby, cluster 1) and 19CS0417 (S. Rissen, cluster 1) (Table 5, indicated with an *). In 19CS392, no Col440_1 plasmid was detected, and 19CS0417 carried more ARGs and plasmid replicons than the other strains in the same cluster (Table 5).

The six IncHI1 replicons belonging to the same ST were found in the samples collected in the slaughterhouse (splitting place) and in the market (pork and cutting board). They belonged mostly to different clusters, and they were found in both serovars (Table 5). Although the difference in these plasmids lies in some of the ARGs and their MGEs, all carried multiple ARGs.

\section{DISCUSSION}

Salmonella species is a zoonotic pathogen of major importance due to the high number of human infections and bacterial isolates with an increasing antibiotic resistance (38). In Vietnam, the main reservoirs are food-producing animals (3) such as pigs, where Salmonella is widely disseminated along the pig value chain. In this study, 23 isolates from the pig value chain were analyzed. They belonged to two important serovars in Vietnam, i.e., S. Rissen (5) ST469, which is distributed around the world $(39,61)$, and $S$. Derby ST40 $(4,9)$, which is one of the most common STs found in pork and poultry (40).

In Vietnam, the prevalence of Salmonella with AMR is high in pork, other retail meat, and seafood products $(12,13)$. Most of them are resistant against tetracycline, trimethoprimsulfamethoxazole, chloramphenicol, and ampicillin $(5,9,12)$. This is comparable to our study, where high resistance was detected against ampicillin (73.9\%) and trimethoprim and trimethoprim/sulfamethoxazole (both 56.5\%, Table 2), but not against tigecycline (17.4\%).

In this study, all sequenced isolates carried at least one ARG. These genes conferred resistance to 11 antibiotic classes. In other Vietnamese studies, genes against 8 (13) and 11 (41) antibiotic classes were also found. In this study, the most frequently detected ARGs were against tetracycline, $\beta$-lactam antibiotics, chloramphenicol, and trimethoprimsulfamethoxazole (Table 3 ). This had been also detected in previous publications on Vietnamese pigs $(5,9,12,13,42)$. Genes tet $A$ and/or tet $M$ were identified in all isolates (Table 3), such as in pigs, sampled in 2019 in the same country (13). The bla TEM.1 and/or bla $a_{L A P}$, genes were detected in $65.21 \%$ (Table 3) of the isolates, which were also identified in Vietnamese Salmonella strains identified in pigs (13) and humans (41). Almost all ARGs detected in those studies were previously observed in Vietnamese strains $(13,41)$. The exception was the detection of fosA7.3; this gene was found in $56.5 \%$ of the samples. This high prevalence was also observed recently in France (43) and in Germany (44).
FosA was included recently in the Resfinder database, which determines the importance of keeping track of the updates of public databases (43). No ESBL- and AmpC-producing isolates were detected in our study, whereas in other published studies in Vietnam, such strains were also detected in pigs (5) and in humans (41). One isolate carried $m c r-1$ (Table 3), which was also detected in Vietnamese pigs (8) and poultry samples (14).

Furthermore, MDR Salmonella species are also widely disseminated in Vietnamese pigs $(5,8)$, poultry (13), seafood (5), and humans (41). In our study, $69 \%$ of the strains were MDR, and $S$. Derby carried more ARGs than S. Rissen. This high multidrug resistance prevalence could be related to the use of large amounts of antimicrobials to treat infections, as well as to increase the productivity of animal farming (8). Making proper antimicrobial treatment using phenotypical and/or genotypical AMR detection (45) is one of the solutions for the reduction of the use of antimicrobials and for the dropping of resistance against first-line antimicrobials (46). For example, in this study, most $S$. Derby isolates were multiresistant (Table 1); thus, in the case of animal treatment, only the last-resort antibiotics, such as second- and third-generation cephalosporins, could be used. Nevertheless, these antibiotics are critically important for human treatment (47). S. Rissen isolates were mostly resistant against tetracycline (Table 1); a possible treatment for these animals would be florfenicol in feed, which is frequently used in Vietnam (48). However, other measures must be taken. For example, in Vietnam, there is a decree $(13 / 2020 / \mathrm{ND}-\mathrm{CP})$ that sets the timeframe (between 2021 and 2026) for a ban on antimicrobials for prophylactic purposes in feed and animals, which was enacted in 2020 (49). In addition, the improvement of management practices and the use of vaccines and probiotics are the alternatives against growth-promoting and prophylactics (50).

In most isolates, there is a lack of correspondence between the detected phenotype and the genotype in at least one of the antibiotic-resistant families. This may be due to inadequate gene expression, which has been shown to be a barrier against drug resistance detection (51) or because the isolates have an MIC one dilution step above the ECOFF (52). In the case of aminoglycosides, only four strains were detected as resistant, and these strains presented from one up to three genes against aminoglycosides (Table 4). This could be related to the problem that Salmonella species does not show resistance against aminoglycosides in vitro (53). In the case of the tetracycline family, all the isolates presented at least one ARG (tetA and/or tet $M$ ); nevertheless, 14 strains were determined as wild type by the VITEK 2 Compact System. An explanation could be that the VITEK cards used in this study contain only tigecycline. The gene tet $A$ decreases to some extent the sensitivity to tigecycline in Salmonella species (54), and tetM seems not to be a determinant in the resistance against tigecycline (13). The gene fos $A 7$ and fos $A 7.3$ have been previously detected in $S$. Derby in France, but no resistance in vitro has been tested (43). S. Heidelberg shows a high level of resistance when this gene was located in plasmids (55); however, in this study, all $S$. Derby isolates that carried fosA7.3 were susceptible in both VITEK 2 Compact System (Table 4) and Micronaut AST-system (Supplementary Table 2). For this reason, further investigations must be done to validate the fosA7.3 functionality in $S$. Derby. 
In conclusion, these discordances show that the genotypical determination of the AMR could add relevant information to the phenotypic detection.

Plasmids are usual vehicles for ARGs and can be spread by horizontal gene transfer even between broadly divergent bacteria $(15,56,57)$. In this study, $95.6 \%(22 / 23)$ of the isolates carried at least one plasmid replicon. Col-plasmid replicons (Table 1) were detected in $91.3 \%(21 / 23)$ of the strains. These small mobilizable plasmids encode the bacteriocin colicin (15), and they have been frequently found in Salmonella species in the United States (58). However, plasmids of incompatibility groups IncI, IncFI, IncN, and IncHI carried the highest variety of ARGs in Salmonella enterica $(16,17)$. In this study, $34.7 \%(8 / 23)$ of the isolates carried at least one of these replicons (Table $\mathbf{1}$ ).

The IncHI plasmid is mostly found in Salmonella $(15,16$, $59)$. This plasmid replicon was detected in $26.1 \%(6 / 23)$ of the samples. They belonged to the same MLST (unknown, nearest ST:16). Furthermore, plasmid p19CS0402-IncHI1 harbored an IncFIA replicon; this is a multireplicon MDR IncHI1/IncFIA type found previously in an Escherichia coli strain collected in China (60). This replicon was also found in strains 19CS0400, 19CS0401, and 19CS0403 (Tables 1, 5). Plasmids shared a common backbone (core genes and genes for replication, maintenance, and transmission), but the differences are MGE and ARGs, as described in previous studies $(15,16,56)$.

Multiple ARGs are frequently carried by IncHI $(16,56)$. In this study, IncHI1 plasmid sequences carried between 3 and 10 ARGs. Genes tet $M$ and $q n r S 1$ were present in all strains, but other genes, such as folP2, qacE, ant1_2, cmlA1, ant1_3, and dfrA_12 bla $a_{\mathrm{TEM}}$, were also found in the plasmids. These MGEs, ARGs, and other accessory regions are acquired during the spread of the plasmid $(16,56)$, making IncHI larger than the other conjugative plasmids (15).

In this study, phylogenetic SNP analysis detected 10 clusters (Table 5). Five (three $S$. Derby and two $S$. Rissen) grouped together isolates of the slaughterhouse (splitting place, worker hands, and swab on pig carcass) and the market (pork and cutting board) (Table 5), suggesting a transmission of Salmonella from the slaughterhouse to the market. Furthermore, in three clusters (Table 5), Salmonella was found on the workers' hands and on the carcasses at the slaughterhouse. This suggests that cross-contamination of carcasses may happen by the handling of the workers or other procedures at the slaughterhouse (4). This shows the importance of sanitation and good hygienic procedures during slaughtering. These measures are necessary for the control and reduction of Salmonella transmission in pork meat (13).

Almost all clusters contained isolates with the same ARGs and plasmid replicons (Table 3). For example, $S$. Derby cluster 2 carried isolates with $13 \mathrm{ARG}$ and 2 replicons. These isolates were found in the slaughterhouse and on a cutting board at the market (Table 5), again suggesting the possible transfer of Salmonella and their resistance genes between the slaughterhouse and the market. This kind of transmission was detected in a previous study in Vietnam (12).

However, possible ARG transmission was not only seen within single clusters. Six isolates that belonged to serovars Rissen and Derby and belonged to four different clusters (based on SNP typing, Table 5, gray cells) carried an MDR IncHI1 plasmid with identical plasmid ST. These isolates were found in the slaughterhouse (splitting place) and at the market (pork and cutting board, Table 5, gray cells). Observations like this reveal the potential spread and distribution of a plasmid transmitting multidrug resistance in different clusters and serovars along the pig value chain.

Limitations to this study include the moderate number of strains obtained from samples from Vietnam. However, the data presented here highlight the importance of antibiotic resistance among Salmonella strains in Vietnamese pigs and show its potential spread to humans. Furthermore, a comparison of our strains with the same serovar and ST from pigs slaughtered in Vietnam was not possible because of the limited number of public sequences strain with the same characteristic as our strains. For this reason, our publication will add information to increase the number of sequence data to the public databases.

\section{CONCLUSIONS}

Here, we report an analysis of $13 \mathrm{~S}$. Derby and $10 \mathrm{~S}$. Rissen isolates, collected in 2013 at various stages in pig slaughterhouses and pork markets in Vietnam. VITEK 2 Compact System determined AMR phenotype, and WGS was used for revealing ARGs, plasmids, and the phylogenetic relationships between the strains. The $86.9 \%(20 / 23)$ of the samples were resistant to at least one antibiotic, and all isolates carried at least one ARG, whereas $69.5 \%$ (16/23) of them were MDR. The most frequently detected ARGs conferred resistance against tetracycline, $\beta$-lactam antibiotics, chloramphenicol, and sulfonamide. One isolate carried $m c r-1$, but no ESBL- and AmpC-encoded genes were found in any of the isolates. However, the relation between the phenotype and the ARGs was discordant in the samples. Some of the ARGs were found on plasmids such as IncHI1, which accounted for $26.1 \%$ of the samples and carried between 3 and 10 ARGs. SNP analysis showed the potential of transmission of MDR Salmonella from slaughterhouse to market via the pork chain. Based on data from this study, ARGs, located in IncHI1 plasmids, could be a potential factor for the spread of multidrug resistance among clusters, serovars, and along the chain.

To investigate the MDR situation in the Vietnam pig value chain, further studies should be done using WGS to identify ARGs and track MDR strains and plasmids. In addition, the location of ARGs in plasmids or the chromosome could help to monitor and control the spread of ARGs. WGS and bioinformatics tools should be introduced as a standard procedure to help the identification of critical points within pork production chains to control the spread of antimicrobialresistant Salmonella.

\section{DATA AVAILABILITY STATEMENT}

The datasets presented in this study can be found in online repositories. The names of the repository/repositories and accession number(s) can be found in the article//Supplementary Material. 


\section{ETHICS STATEMENT}

Ethical review and approval was not required for the animal study because Samples were collected from slaughterhouse and market environmental samples, pork meat and carcasses.

\section{AUTHOR CONTRIBUTIONS}

BG-S, RF, and HT contributed to conception and design of the study. BG-S performed the laboratory work and wrote the manuscript. BG-S and SG-S bioinformatic analysis. SD-X collected the samples. MA-G performed the minion sequencing. DM and RF provided the samples. All authors contributed to manuscript revision, read, and approved the submitted version.

\section{FUNDING}

For this work, BG-S and SG-S were supported by in-house projects of the Friedrich-Loeffler-Institut on AMR-One Health.

\section{REFERENCES}

1. OIE. Terrestrial Animal Health Code II. (2019). Available online at: https:// www.oie.int/en/what-we-do/standards/codes-and-manuals/terrestrial-codeonline-access/

2. Yen NTP, Nhung NT, Van NTB, Cuong NV, Chau LTT, Trinh HN, et al. Antimicrobial residues, non-typhoidal Salmonella, Vibrio spp. and associated microbiological hazards in retail shrimps purchased in Ho Chi Minh city (Vietnam). Food Control. (2020) 107:106756. doi: 10.1016/j.foodcont.2019.106756

3. Connor TR, Owen SV, Langridge G, Connell S, Nair S, Reuter S, et al. What's in a Name? Species-wide whole-genome sequencing resolves invasive and noninvasive lineages of salmonella enterica serotype paratyphi B. MBio. (2016) 7:e00527-16. doi: 10.1128/mBio.00527-16

4. Dang-Xuan S, Nguyen-Viet H, Pham-Duc P, Unger F, Tran-Thi N, Grace D, et al. Risk factors associated with Salmonella spp. prevalence along smallholder pig value chains in Vietnam. Int J Food Microbiol. (2019) 290:10515. doi: 10.1016/j.ijfoodmicro.2018.09.030

5. Nguyen DTA, Kanki M, Do Nguyen P, Le HT, Ngo PT, Tran DNM, et al. Prevalence, antibiotic resistance, and extended-spectrum and AmpC betalactamase productivity of Salmonella isolates from raw meat and seafood samples in Ho Chi Minh City, Vietnam. Int J Food Microbiol. (2016) 236:11522. doi: 10.1016/j.ijfoodmicro.2016.07.017

6. Lan TTQ, Gaucher ML, Nhan NTM, Letellier A, Quessy S. Distribution of virulence genes among Salmonella serotypes isolated from pigs in Southern Vietnam. J Food Prot. (2018) 81:1459-66. doi: 10.4315/0362-028X.JFP17-408

7. Le Bas C, Tran TH, Nguyen TT, Dang DT, Ngo CT. Prevalence and epidemiology of Salmonella spp. in small pig abattoirs of Hanoi, Vietnam. Ann N Y Acad Sci. (2006) 1081:269-72. doi: 10.1196/annals.1373.035

8. Nhung NT, Van NTB, Cuong NV, Duong TTQ, Nhat TT, Hang TTT, et al. Antimicrobial residues and resistance against critically important antimicrobials in non-typhoidal Salmonella from meat sold at wet markets and supermarkets in Vietnam. Int J Food Microbiol. (2018) 266:301-9. doi: 10.1016/j.ijfoodmicro.2017.12.015

9. Ellerbroek L, Narapati D, Phu Tai N, Poosaran N, Pinthong R, Sirimalaisuwan A, et al. Antibiotic resistance in Salmonella isolates from imported chicken carcasses in Bhutan and from pig carcasses in Vietnam. J Food Prot. (2010) 73:376-9. doi: 10.4315/0362-028X-73.2.376

10. WHO. Global Antimicrobial Resistance Surveillance System (GLASS) Report: Earlyimplementation 2020. (2020). Available online at: https://apps.who.int/ iris/handle/10665/332081

\section{ACKNOWLEDGMENTS}

We thank Jörg Linde for support on the bioinformatics servers, Fiona Balzer and Herlinde Irsigler for skillful technical assistance, and Fabian Steinlechner for his time and support.

\section{SUPPLEMENTARY MATERIAL}

The Supplementary Material for this article can be found online at: https://www.frontiersin.org/articles/10.3389/fvets. 2021.705044/full\#supplementary-material

Supplementary Table 1 | p19CS0402- IncHl1 plasmid annotation.

Supplementary Table 2 | Micronaut AST for Fosfomycin in the 13 S. Derby isolates.

Supplementary Table 3 | Single-nucleotide polymorphism (SNP) analysis.

Supplementary Table 4 | IncHI1 plasmid isolates' identity

percentage comparison.

Supplementary Table 5 | Genome accession number NCBI.

11. Magiorakos AP, Srinivasan A, Carey RB, Carmeli Y, Falagas ME, Giske CG, et al. Multidrug-resistant, extensively drug-resistant and pandrugresistant bacteria: an international expert proposal for interim standard definitions for acquired resistance. Clin Microbiol Infect. (2012) 18:268-81. doi: 10.1111/j.1469-0691.2011.03570.x

12. Nghiem MN, Nguyen VT, Nguyen TTH, Nguyen TD, Vo TTB. Antimicrobial resistance gene expression associated with multidrug resistant Salmonella spp. isolated from retail meat in Hanoi, Vietnam. Int Microbiol. (2017) 20:85-93. doi: 10.2436/20.1501.01.288

13. Nghiem MN, Nguyen VT, Jeung EB, Vo TTB. Alternate antimicrobial resistance genes in multidrug resistant Salmonella spp. isolated from retail meats in Vietnam using RNA-sequencing analysis. J Food Saf. (2019) 39:e12707. doi: 10.1111/jfs.12707

14. Trung NV, Matamoros S, Carrique-Mas JJ, Nghia NH, Nhung NT, Chieu TTB, et al. Zoonotic transmission of mcr-1 colistin resistance gene from small-scale poultry farms, Vietnam. Emerg Infect Dis. (2017) 23:529-32. doi: 10.3201/eid2303.161553

15. Partridge SR, Kwong SM, Firth N, Jensen SO. Mobile genetic elements associated with antimicrobial resistance. Clin Microbiol Rev. (2018) 31:e00088-17. doi: 10.1128/CMR.00088-17

16. Kubasova T, Cejkova D, Matiasovicova J, Sekelova Z, Polansky O, Medvecky $\mathrm{M}$, et al. Antibiotic resistance, core-genome and protein expression in IncHI1 plasmids in Salmonella Typhimurium. Genome Biol Evol. (2016) 8:1661-71. doi: $10.1093 /$ gbe/evw105

17. Rozwandowicz M, Brouwer MSM, Fischer J, Wagenaar JA, GonzalezZorn B, Guerra B, et al. Plasmids carrying antimicrobial resistance genes in Enterobacteriaceae. J Antimicrob Chemother. (2018) 73:1121-37. doi: $10.1093 / \mathrm{jac} / \mathrm{dkx} 488$

18. García-Soto S, Abdel-Glil MY, Tomaso H, Linde J, Methner U. Emergence of multidrug-resistant Salmonella enterica subspecies enterica serovar infantis of multilocus sequence type 2283 in German broiler farms. Front Microbiol. (2020) 11:1741. doi: 10.3389/fmicb.202 0.01741

19. Lettini AA, Than TV, Marafin E, Longo A, Antonello K, Zavagnin P, et al. Distribution of Salmonella serovars and antimicrobial susceptibility from poultry and swine farms in central Vietnam. Zoonoses Public Health. (2016) 63:569-76. doi: 10.1111/zph.12265

20. EUCAST. Breakpoint Tables for Interpretation of MICs and Zone Diameters. Version 9.0, 2019 (2019). Available online at: http://www.eucast.org.

21. Seemann T. Shovill GitHub. Assemble Bacterial Isolate Genomes From Illumina Paired-End Reads. (2018). Available online at: https://github.com/tseemann/ shovill (accessed February 25, 2021). 
22. Gurevich A, Saveliev V, Vyahhi N, Tesler G. QUAST: quality assessment tool for genome assemblies. Bioinformatics. (2013) 29:1072-5. doi: 10.1093/bioinformatics/btt086

23. Seemann T. Prokka: rapid prokaryotic genome annotation. Bioinformatics. (2014) 30:2068-9. doi: 10.1093/bioinformatics/btu153

24. Wood DE, Lu J, Langmead B. Improved metagenomic analysis with Kraken 2. Genome Biol. (2019) 20:257. doi: 10.1186/s13059-0191891-0

25. Feldgarden $M$, Brover V, Haft DH, Prasad AB, Slotta DJ, Tolstoy I, et al. Validating the amrfinder tool and resistance gene database by using antimicrobial resistance genotype-phenotype correlations in a collection of isolates. Antimicrob Agents Chemother. (2019) 63:e00483-19. doi: 10.1128/AAC.00483-19

26. Jia B, Raphenya AR, Alcock B, Waglechner N, Guo P, Tsang KK, et al. CARD 2017: expansion and model-centric curation of the comprehensive antibiotic resistance database. Nucleic Acids Res. (2017) 45:D566-73. doi: 10.1093/nar/gkw1004

27. Zankari E, Hasman H, Cosentino S, Vestergaard M, Rasmussen S, Lund O, et al. Identification of acquired antimicrobial resistance genes. J Antimicrob Chemother. (2012) 67:2640-4. doi: 10.1093/jac/dks261

28. Carattoli A, Hasman H. PlasmidFinder and in silico pMLST: identification and typing of plasmid replicons in whole-Genome Sequencing (WGS). Methods Mol Biol. (2020) 2075:285-94. doi: 10.1007/978-1-4939-98 77-7_20

29. Yoshida CE, Kruczkiewicz P, Laing CR, Lingohr EJ, Gannon VP, Nash JH, et al. The Salmonella In Silico Typing Resource (SISTR): an open webaccessible tool for rapidly typing and subtyping draft Salmonella genome assemblies. PLoS ONE. (2016) 11:e0147101. doi: 10.1371/journal.pone.01 47101

30. Price MN, Dehal PS, Arkin AP. FastTree: computing large minimum evolution trees with profiles instead of a distance matrix. Mol Biol Evol. (2009) 26:1641-50. doi: 10.1093/molbev/msp077

31. Letunic I, Bork P. Interactive Tree Of Life (iTOL) v4: recent updates and new developments. Nucleic Acids Res. (2019) 47:W256-9. doi: 10.1093/nar/gkz239

32. Kolmogorov M, Yuan J, Lin Y, Pevzner PA. Assembly of long, errorprone reads using repeat graphs. Nat Biotechnol. (2019) 37:540. doi: 10.1038/s41587-019-0072-8

33. Vaser R, Sovic I, Nagarajan N, Sikic M. Fast and accurate de novo genome assembly from long uncorrected reads. Genome Res. (2017) 27:737-46. doi: 10.1101/gr.214270.116

34. Walker BJ, Abeel T, Shea T, Priest M, Abouelliel A, Sakthikumar S, et al. Pilon: an integrated tool for comprehensive microbial variant detection and genome assembly improvement. PloS ONE. (2014) 9:e112963. doi: 10.1371/journal.pone.0112963

35. Darling ACE, Mau B, Blattner FR, Perna NT. Mauve: multiple alignment of conserved genomic sequence with rearrangements. Genome Res. (2004) 14:1394-403. doi: 10.1101/gr.2289704

36. Grimont P, Weill FX. Antigenic Formulae-Grimont-Weill.pdf. 9th dn. WHO Collaborating Center for Reference and Research on Salmonella, Institut Pasteur. (2007)

37. EUCAST. Redefining Susceptibility Testing Categories S, I and R. (2019). Available online at: http://www.eucast.org/fileadmin/src/media/PDFs/ EUCAST_files/EUCAST_Presentations/2018/EUCAST_-_Intermediate_ category_-_information_for_all.pdf

38. Forshell LP, Wierup M. Salmonella contamination: a significant challenge to the global marketing of animal food products. Rev Sci Tech. (2006) 25:541-54. doi: $10.20506 /$ rst.25.2.1683

39. Campos J, Mourao J, Peixe L, Antunes P. Non-typhoidal Salmonella in the pig production Chain: a comprehensive analysis of its impact on human health. Pathogens. (2019) 8:19. doi: 10.3390/pathogens 80 10019

40. Sévellec Y, Felten A, Radomski N, Granier SA, Le Hello S, Petrovska L, et al. Genetic diversity of Salmonella Derby from the poultry sector in Europe. Pathogens. (2019) 8;46. doi: 10.3390/pathogens80 20046

41. Duong VT, The HC, Nhu TDH, Tuyen HT, Campbell JI, Minh PV, et al. Genomic serotyping, clinical manifestations, and antimicrobial resistance of nontyphoidal salmonella gastroenteritis in hospitalized children in
Ho Chi Minh City, Vietnam. J Clin Microbiol. (2020) 58:e01465-20. doi: 10.1128/JCM.01465-20

42. Schutzius G, Nguyen M, Navab-Daneshmand T. Antibiotic resistance in fecal sludge and soil in Ho Chi Minh City, Vietnam. Environ Sci Pollut Res. (2019) 26, 34521-30. doi: 10.1007/s11356-019-06537-5

43. Sévellec Y, Granier SA, Le Hello S, Weill FX, Guillier L, Mistou MY, et al. Source attribution study of sporadic Salmonella Derby cases in France. Front Microbiol. (2020) 11:889. doi: 10.3389/fmicb.2020. 00889

44. González-Santamarina B, García-Soto S, Hotzel H, Meemken D, Fries R, Tomaso H. Salmonella Derby: a comparative genomic analysis of strains from Germany. Front Microbiol. (2021). 12:1259. doi: 10.3389/fmicb.2021. 591929

45. Ellington MJ, Ekelund O, Aarestrup FM, Canton R, Doumith M, Giske C, et al. The role of whole genome sequencing in antimicrobial susceptibility testing of bacteria: report from the EUCAST Subcommittee. Clin Microbiol Infect. (2017) 23:2-22. doi: 10.1016/j.cmi.2016.11.012

46. Kingsley RA, Msefula CL, Thomson NR, Kariuki S, Holt KE, Gordon MA, et al. Epidemic multiple drug resistant Salmonella Typhimurium causing invasive disease in sub-Saharan Africa have a distinct genotype. Genome Res. (2009) 19:2279-87. doi: 10.1101/gr.091017.109

47. WHO. Critically Important Antimicrobials for Human Medicine. (2019). Available online at: https://apps.who.int/iris/bitstream/handle/10665/312266/ 9789241515528-eng.pdf

48. Cuong NV, Nhung NT, Nghia NH, Hoa NTM, Trung NV, Thwaites G, et al. Antimicrobial consumption in medicated feeds in Vietnamese pig and poultry production. Ecohealth. (2016) 13:490-8. doi: 10.1007/s10393-016-1 $130-\mathrm{z}$

49. Cuong NV, Kiet BT, Hien VB, Truong BD, Phu DH, Thwaites G, et al. Antimicrobial use through consumption of medicated feeds in chicken flocks in the Mekong Delta of Vietnam: a three-year study before a ban on antimicrobial growth promoters. PLOS ONE. (2021) 16:e0250082. doi: 10.1371/journal.pone.0250082

50. McEwen SA, Fedorka-Cray PJ. Antimicrobial use and resistance in animals. Clin Infect Dis. (2002) 34:S93-S106. doi: 10.1086/340246

51. Andres P, Lucero C, Soler-Bistue A, Guerriero L, Albornoz E, Tran T, et al. Differential distribution of plasmid-mediated quinolone resistance genes in clinical enterobacteria with unusual phenotypes of quinolone susceptibility from Argentina. Antimicrob Agents Chemother. (2013) 57:246775. doi: 10.1128/AAC.01615-12

52. Bortolaia V, Kaas RS, Ruppe E, Roberts MC, Schwarz S, Cattoir V, et al. ResFinder 4.0 for predictions of phenotypes from genotypes. J Antimicrob Chemother. (2020) 75:3491-500. doi: 10.1093/jac/dk aa345

53. Leclercq R, Canton R, Brown DFJ, Giske CG, Heisig P, MacGowan AP, et al. EUCAST expert rules in antimicrobial susceptibility testing. Clin Microbiol Infect. (2013) 19:141-60. doi: 10.1111/j.1469-0691.2011.0 3703.x

54. Akiyama T, Presedo J, Khan AA. The tetA gene decreases tigecycline sensitivity of Salmonella enterica isolates. Int J Antimicrob Agents. (2013) 42:133-40. doi: 10.1016/j.ijantimicag.2013.04.017

55. Rehman MA, Yin XH, Persaud-Lachhman MG, Diarra MS. First detection of a fosfomycin resistance gene, fosa7, in Salmonella enterica serovar Heidelberg isolated from broiler chickens. Antimicrob Agents Chemother. (2017) 61:e00410-17. doi: 10.1128/AAC.00410-17

56. Álvarez S. Comparative genomics and phylogeny of sequenced IncHI plasmids. bioRXiv. (2019) 334409. doi: 10.1101/ 334409

57. Bleicher A, Schofl G, Rodicio MD, Saluz HP. The plasmidome of a Salmonella enterica serovar Derby isolated from pork meat. Plasmid. (2013) 69:202-10. doi: 10.1016/j.plasmid.2013.01.001

58. Pornsukarom S, van Vliet AHM, Thakur S. Whole genome sequencing analysis of multiple Salmonella serovars provides insights into phylogenetic relatedness, antimicrobial resistance, and virulence markers across humans, food animals and agriculture environmental sources. BMC Genomics. (2018) 19:801. doi: 10.1186/s12864-018-5137-4

59. Holt KE, Thomson NR, Wain J, Phan MD, Nair S, Hasan R, et al. Multidrugresistant Salmonella enterica serovar Paratyphi A harbors IncHI1 plasmids 
similar to those found in serovar Typhi. J Bacteriol. (2007) 189:4257-64. doi: 10.1128/JB.00232-07

60. Li RC, Du PC, Zhang P, Li Y, Yang XR, Wang ZQ, et al. Comprehensive genomic investigation of coevolution of mcr genes in Escherichia coli strains via nanopore sequencing. Global Challenges. (2021) 5:2000014. doi: $10.1002 /$ gch 2.202000014

61. Pornsukarom S, Patchanee P, Erdman M, Cray PF, Wittum T, Lee J, et al. Comparative phenotypic and genotypic analyses of Salmonella Rissen that originated from food animals in Thailand and United States. Zoonoses Public Health. (2015) 62:151-8. doi: 10.1111/zph.12144

Conflict of Interest: The authors declare that the research was conducted in the absence of any commercial or financial relationships that could be construed as a potential conflict of interest.
Publisher's Note: All claims expressed in this article are solely those of the authors and do not necessarily represent those of their affiliated organizations, or those of the publisher, the editors and the reviewers. Any product that may be evaluated in this article, or claim that may be made by its manufacturer, is not guaranteed or endorsed by the publisher.

Copyright (c) 2021 González-Santamarina, García-Soto, Dang-Xuan, Abdel-Glil, Meemken, Fries and Tomaso. This is an open-access article distributed under the terms of the Creative Commons Attribution License (CC BY). The use, distribution or reproduction in other forums is permitted, provided the original author(s) and the copyright owner(s) are credited and that the original publication in this journal is cited, in accordance with accepted academic practice. No use, distribution or reproduction is permitted which does not comply with these terms. 